\title{
A Framework for Incorporating EROI into Electrical Storage
}

\author{
Graham Palmer ${ }^{1}$
}

Received: 24 July 2016 / Accepted: 11 April 2017 / Published online: 19 April 2017

(C) Springer International Publishing Switzerland 2017

\begin{abstract}
The contribution from variable renewable energy (VRE) to electricity generation is projected to increase. At low penetration, intermittency can usually be accommodated at low cost. High-penetration VRE will displace conventional generation, and require increased grid flexibility, geographic and technology diversity, and the use of electrical storage. Energy return on investment (EROI) is a tool that gives greater weight to the principles of energetics over market prices, and may provide a longterm guide to prospective energy transitions. The EROI of electrical storage may be critical to the efficacy of highpenetration renewable scenarios. However, there is no generally agreed upon methodology for incorporating storage into EROI. In recent years, there have been important contributions to applying net-energy analysis to storage, including the development of storage-specific net-energy metrics. However, there remains uncertainty as to how to apply these metrics to practical systems to derive useful or predictive information. This paper will introduce a framework for evaluating storage at a system level. It introduces the surplus energy-storage synergy hypothesis as a general principle for exploring the role of storage. It is argued that the useful energy available to society is determined by both the net-energy of the energy source and the stored energy as stocks. This hypothesis is translated across to electricity systems with the use of electrical reliability indices to evaluate the value of storage. A case study applies the framework to a suite of VRE simulations. The case study
\end{abstract}

Graham Palmer

graham.palmer@climate-energy-college.org;

graham@paltech.com.au

1 Australian-German College of Energy and Climate, The University of Melbourne, Melbourne, Australia was modelled as a limiting case of VRE plus storage, and is therefore not intended as a comprehensive cost-optimised solution to high-penetration VRE. A shift from an electrical system based mostly on energy stocks to one based mostly on natural flows is constrained by the quantity of storage required, and the quantity of VRE overbuild to charge the stores. The application of the framework shows that the value of electrical storage and overbuild exhibits a marked diminishing returns behaviour at rising VRE penetration and therefore the first units of storage are the most valuable. The framework is intended to stimulate further research into using EROI to better understand the role of VRE and storage in prospective energy transitions.

Keywords Storage $\cdot$ EROI $\cdot$ Renewables $\cdot$ Energy surplus

\section{Introduction}

\section{Overview}

Regardless of climate goals, the contribution from renewable energy is projected to increase significantly over the medium to long term (Krey and Clarke 2011). The IPCC AR5 $450 \mathrm{ppm}$ suite of energy scenarios (Edenhofer et al. 2014 , p. 12) are characterised by rapid improvements in energy efficiency, and a significant scaling up of the share of low-carbon energy supply. Nearly all substantially increase the deployment of renewables, many deploy an increasing share from nuclear and/or fossil fuels with carbon capture and sequestration (CCS), and some include the possibility of bioenergy with carbon capture and storage (BECCS). All of these options have net-energy implications, and some (e.g. nuclear and CCS) face additional barriers and risks (Edenhofer et al. 2014, pp. 20-22). 
At low penetration, intermittency can usually be accommodated at low cost (Gross et al. 2006). High-penetration RE will displace conventional generation, and require increased grid flexibility, geographic and technology diversity, and the use of electrical storage (Denholm and Hand 2011).

The need for storage increases the energy burden of electricity supply systems, and thus lowers the EROI (Carbajales-Dale et al. 2014). However, there is ongoing debate as to how much storage will be required in a shift to an electrical system based mostly on VRE, and whether this represents an additional but affordable cost, or a fundamental constraint on VRE penetration (Morgan 2014). Although there are estimates of the embodied energy of storage from the life-cycle literature, there is no agreed methodology on how to apply these estimates to a comprehensive estimate of EROI (Pickard 2014a).

\section{Definition of EROI}

EROI is a unitless ratio, defined as the ratio of the gross flow of energy $E_{g}$ over the lifetime of the project, and the sum of the energy for construction $E_{c}$, operation $E_{o p}$, and decommissioning $E_{d}$ (Murphy et al. 2011, Eq. 1). More generally, Murphy and Hall (2010) state that "EROI is the ratio of how much energy is gained from an energy production process compared to how much of that energy (or its equivalent from some other source) is required to extract, grow, etc., a new unit of the energy in question".

$E R O I=\frac{E_{g}}{E_{c}+E_{o p}+E_{d}}$

Although there is usually general agreement on the concept of EROI (i.e. energy out/energy in), there is a divergence of objectives and methodologies (Carbajales-Dale et al. 2015; Pickard 2014a). The divergence is perhaps most acute with VRE, compared to say oil, because VRE does not substitute one-for-one with conventional generation, with uncertainty related to the allocation of energy costs for integration and storage. Unlike oil, which is pervasive and substitutable, VRE produces electricity, which has high utility but is not globally fungible and currently makes up only $18 \%$ of global total final energy consumption (International Energy Agency (IEA) 2016, p. 28).

\section{Storage Literature Review}

Much of the literature that explores the value of storage has focused on the relationship between storage and markets, and the potential for storage to add value within incumbent systems [e.g. McConnell et al. (2015); Salles et al. (2016)]. Some of the analyses explore a strategic network role (i.e. supporting networks rather than contributing to bulk generation) and the potential role of technological disruption of distributed solar and storage, although much of the disruption is occurring within markets, rather than in transformations of the physical systems.

There have been a number of approaches taken to include the embodied energy of storage into a system-level EROI analysis. Much of the analysis has attempted to isolate storage devices to determine a device-specific EROI. The main weakness to date has been establishing a dynamic function for incorporating storage into EROI.

Barnhart and Benson (2013) defined the metric Energy stored on invested (ESOI), defined as the ratio of electrical energy stored over the lifetime of a storage device, to the embodied primary energy required to build the device. In contrast, Weißbach et al. (2013) considered the storage capacity of the storage device (in this case, pumped hydro storage) required to provide an equivalent baseload role for VRE. Both of these approaches try to ascertain the embodied energy debt of storage, but may not reflect the differing value of storage depending on their role and context. Weißbach assumed a baseload role with 10 days of storage; however, it is not clear why 10 days should be a reference and a high-VRE scenario would value other characteristics, especially flexibility. Furthermore, Raugei (2013) noted some methodology inconsistencies that reflect differing approaches to net-energy analysis.

Barnhart et al. (2015) provided a broader context for the role of storage by exploring the various trade-offs between curtailment, storage, and greenhouse emissions. The tradeoff was illustrated with the use of a graphic that depicted energy intensity (as a proxy for EROI) versus carbon intensity. The plot encompassed both generation and storage devices. It was dissected into four quadrants; 'do today', reflecting options that are worthwhile; 'reduce emissions' and 'improve EROI', as prospective options requiring further development; and 'avoid', reflecting options that have a poor EROI and poor emission performance.

Using the specific context of off-grid rooftop solar, Palmer (2013) considered the role of storage within the context of an overall system. In this case, the role of storage and surplus solar capacity (to ensure adequate winter supply) in a rooftop solar system was evaluated to establish the lifetime EROI of the complete system.

Denholm and Kulcinski (2004) is representative of studies that are measuring the embodied energy of storage devices, but not attempting to account for the relative value that storage provides. In this case, pumped hydro storage (PHS) was evaluated, along with compressed air storage (CAES) and large-scale batteries. Denholm and Kulcinski were concerned with establishing the life-cycle parameters for a given power capacity (GW) rather than a given storage capacity $(\mathrm{GWh})$. 


\section{Renewable Simulation Literature Review}

This study will apply the framework to a renewable energy simulation. Although there are many published regional VRE simulations [e.g. Budischak et al. (2012); Jacobson et al. (2015)], few apply or publish a loss-of-load probabilistic assessment, or explicitly include reserve margins. Where a reserve margin has been applied, it is usually applied as a simple exogenous multiplier rather than emerging from the probabilistic assessment [e.g. (MacDonald et al. 2016b, pg. 32)]. These are described as 'first order' demand-balance simulations (see Hart et al. (2012)) and could be regarded as high-level, exploratory studies rather than the 'second-order' system-level reliability analyses typically carried out by electrical system operators.

\section{Storage Requirements}

Storage requirements of VRE are dominated by stretches of low-wind and solar resource (the 'big gaps' problem) (Lenzen et al. 2016). The ratio between the average monthly solar insolation between summer and winter varies greatly across geographic regions (PV Education 2016). Low latitude regions, such as Singapore, show a relatively small summer/winter ratio of 1.3-1.7, rising to 3-4 in the midlatitudes such as Nevada USA, and above 10 for higher latitudes, such as London. Cloud cover is also region dependent, with clear skies and low aerosols typically located in the latitudes from $15^{\circ}$ to $40^{\circ}$ north or south (International Energy Agency (IEA) 2014). Concentrated solar thermal requires high direct normal radiation (DNI) and is usually located in arid regions in the subtropical band. Winter insolation and extended cloudy periods define the storage requirements for systems reliant on solar.

In the case of wind, geographic dispersion, the physical inertia of wind machines, and aggregation provide smoothing of bulk wind power at sub-hourly scales (Archer and Jacobson 2007). At an hourly and above scale, wind speeds are highly correlated within wind regimes, which may span distances of hundreds to thousands of kilometres (Huva et al. 2016). Seasonal variation is usually much less than for solar but multi-day low-wind conditions appear to be a characteristic of many regions (MacKay 2008, p. 187; Oswald et al. 2008), and these low-wind stretches define the quantity of storage or backup capacity required.

In a review of VRE storage, Pickard (2014b) assumed that around 7 days of storage would be required in a highpenetration VRE scenario. In a simulation for the PJM network in the US, Budischak et al. (2012) used between 9 and $72 \mathrm{~h}$ storage, with 3-times VRE overbuild, which included maintaining a significant share of the legacy fossil fuel capacity, operating as infrequent reserve capacity. Abdulla et al. (2014) found that $58 \mathrm{~h}$ of storage (calculated at $1500 \mathrm{GWh}$ and $25.5 \mathrm{GW}$ demand) would be required for a high PV scenario in Australia in an explorative assessment. Oswald et al. (2008) found that around 6 days of storage would be required to cope with continental scale lowwind conditions in Europe.

In a $100 \%$ renewable simulation, including sector coupling (i.e. heat and electricity) for Germany, $55 \mathrm{GWh}$ of battery storage, $60 \mathrm{GWh}$ of PHS, and $62,000 \mathrm{GWh}$ of methane storage was used in the 'medium' scenario (Palzer and Henning 2014, Fig. 3.4). At 500 TWh annual consumption, the storage capacity represents around 45 days of full-load electrical capacity (equated at average annual demand). Likewise for North America (Canada, USA, and Mexico), Aghahosseini et al. (2016) used around 3-times VRE overbuild, around $2000 \mathrm{GWh}$ of battery storage and 174,000-230,000 GWh of methane storage. At $6059 \mathrm{TWh}$ annual consumption, the storage capacity represents around 14 days of full-load electrical capacity.

Much of the scenario literature avoids the problem of large-scale storage by maintaining a significant share of conventional capacity [e.g. Budischak et al. (2012)] or assuming the ready availability of large-scale biomass. For example, Lenzen et al. (2016, Table 2) did not employ conventional electrical storage but used concentrated solar thermal with $15 \mathrm{~h}$ storage (equating to a theoretical $917 \mathrm{GWh}$ of storage), and generated 16,500 GWh with biofuelled powered gas turbines in a simulation for Australia. Assuming the biofuels were used for seasonal storage equates to 21 days of full-load electrical capacity (equated at average annual demand). In a simulation covering the eastern populated regions of Australia, Elliston et al. (2012) employed a similar generation suite, with biofuelled turbine capacity set at $71 \%$ of annual peak demand but at low capacity factor. The resulting $28,000 \mathrm{GWh}$ of electricity generated from biofuels equates to 50 days full-load electrical capacity, assuming seasonal storage. Both of these simulations set the minimisation of biofuels as an objective.

This study is not seeking to prescribe a storage type and only considers the role of electrical storage. Sector coupling (e.g. power-to-heat, power-to-gas, power-to-desalination, vehicle-to-grid), and other forms of storage (e.g. thermal storage in concentrated solar thermal) may offer opportunities to substitute for electrical storage.

\section{Goal Definitions}

Carbajales-Dale et al. (2015) identifies three distinct goal definitions for EROI as it applies to VRE: a descriptive assessment of a particular technology; a comparative assessment of alternative energy technologies; and an exploration of the viability of emerging technologies to completely substitute for the incumbent system. 
As a tool for comparative assessment, net-energy analysis is frequently used to assess the degree to which VRE displaces fossil fuel consumption. For example, Raugei et al. (2012) derived a 'primary energy equivalent' multiplier in conjunction with EROI to describe the equivalent primary energy that is 'virtually returned to society' (i.e. coal or gas that is preserved for alternative uses). Raugei et al. argue that a unit of energy invested in solar significantly reduces the depletion of fossil fuels over the lifetime of the solar system. This is consistent with much of the discussion of VRE as an abatement tool within an incumbent system. From this perspective, it is assumed that the problem is that there is too much readily available fossil fuel and that without policy intervention the IPCC 'representative concentration pathways' (RCPs) at the high-end are more likely (e.g. RCP 6.0, RCP 8.5). Although RCP 8.5 should not be taken as a no-climate-policy reference scenario (Moss et al. 2010), it nonetheless assumes continuing growth in fossil fuel demand (Riahi et al. 2007).

\section{Goal and Scope of the Present Study}

\section{Different Roles of Storage}

This study is focused on the use of storage to buffer or complement VRE, modelled as natural renewable flows. But to date, most of the use of storage in electricity grids has been for arbitrage and time-shifting in conjunction with baseload (Yang and Jackson 2011). It will be argued that the role of storage as a complement to VRE is different to its traditional role with baseload. Furthermore, the output of electrical storage is usually directly substitutable with energy stocks, especially flexible generation (Denholm and Hand 2011)

Storage can also be reduced to the extent that renewable flows coincide with demand, or demand can be modulated with demand management (Schreiber et al. 2015). Furthermore, geographic diversity (Grossmann et al. 2015; Huva et al. 2016; MacDonald et al. 2016a) and resource diversity (Bogdanov and Breyer 2016) provide a quasi-storage role by raising the effective availability factor.

\section{Energy Capital Substitution}

This study will frame EROI in the context of energy capital substitution, rather than fuel substitution (i.e. to what degree can VRE plus storage replace the capital stock of fossil fuel extraction and conversion rather than just supplant the flow of fossil fuels). It is more concerned with assessing the possibility of future energy systems being able to both sustain themselves, and provide society with sufficient surplus energy (Hall et al. 2009).
A justification for focusing on substitution of capital is the German Energiewende. The term 'Energiewende' can be dated to a study by the German Öko-Institut in 1980 (Krause et al. 1981), with the title 'Energy turnaround, growth and prosperity without oil and uranium' (Joas et al. 2016; Maubach 2014). Between the starting point of the EEG in 2003 and 2014, total installed power generation capacity grew by $51 \%$, although total annual generation was virtually unchanged (Bundesministerium für Wirtschaft und Technologie 2015).

The Energiewende has been accompanied by grid expansions and tariff increases, although wholesale spot prices have declined (Poser et al. 2014). Hence the Energiewende is reducing the direct fuel load and $\mathrm{CO}_{2}$ emissions, at a cost, but not replicating the substitution of infrastructure that has typically accompanied historic transitions (i.e. the incentive policies encourage a process of adding to the capital stock rather than substituting away from the legacy capital stock). The tariff increases need to be balanced against the broader societal costs of energy, including substantial German fossil fuel and nuclear subsidies (Morris and Jungjohann 2016; van der Burg and Pickard 2015). One interpretation is that the Energiewende is succeeding in reducing the environmental burden of electricity generation, but that the shift is reliant on the strength of the German economy, the relatively high economic output per unit of energy, and the high EROI of the global energy system.

\section{Reformulation of Storage and EROI}

The contribution of this study is to reformulate the analysis of storage. Firstly, it will be argued that energy storage is a fundamental property of net-energy. An understanding of the transition from hunter-gatherer, through pastoralism and agriculture, the Industrial Revolution, and twentieth century economic development, can be enhanced through supplementing the concept of net-energy with the concept of the energy surplus-storage synergy. This approach follows the precedent of applying behaviours observed in natural ecology to industrial ecology [e.g. Brown et al. (2011)]. In the pre-industrial context, energy referred mostly to food and fodder, but by the twentieth century, energy included a broader range of traded energy sources and biomass (King et al. 2015).

Secondly, the cost structure of electricity systems is dominated by capital-intensive infrastructure and fixed operating costs (Brown and Faruqui 2014). It is the nature of all utilities (e.g. electricity, water, telecommunications) and many public services (e.g. passenger rail) that the infrastructure must be built to meet peak demand. Some services, such as urban transit systems and water supply systems, can dampen peak demand by permitting congestion or using built-in storage. For example, trains can queue 
passengers on platforms during peak periods, allowing congestion to buffer peak demand without the train system failing; the pressure of water supply can fall during summer heat waves, permitting a stressed system to remain functional but at a lower quality of service.

In contrast, the real-time flow limitation of electrical systems does not permit 'soft' congestion management during peak periods. Furthermore, unlike gas or water pipelines, which may store several hours (or days) of product within distribution networks that can be readily drawn down, AC networks do not possess an equivalent 'draw down' capability without storage devices. Instead, infrastructure must be maximally sized to meet reliability standards, although infrastructure requirements could be marginally reduced if reliability standards were relaxed (Australian Productivity Commission 2013).

Finally, a framework for incorporating storage into EROI is presented. This requires calculating EROI of the VRE and storage as a sub-system, and measuring the resulting $E R O I_{V R E+s t o r a g e}$ relative to the displaced capacity of conventional generation. The benefit of measuring the result relative to the displaced capacity is that it is possible to trade-off the rising availability factor with the diminishing returns of marginal storage, thereby overcoming the limitation of arbitrarily setting the quantity of storage and RE overbuild. The result reflects the energy investment to substitute for energy infrastructure, rather than displacing fossil fuel consumption.

\section{Historical Precedents}

\section{Food Storage as a Pivotal Development}

The contemporary value of energy storage is not unique, and a historical parallel can be drawn from the Neolithic transition, beginning around 10,000 years ago. Prior to this period, Palaeolithic man lived a subsistence life of hunting and gathering, governed by the diurnal and seasonal cycles (Diamond 2005).

In the transition, humans began domesticating plants and animals (Hibbs and Olsson 2004). There are different hypotheses for why humans chose to adopt agriculture in the first place (Diamond 2005). But it gradually led to specialised crop cultivation, land clearing, and basic irrigation. These advances permitted seasonal food storage for the first time, increased population density, and represented a prelude to non-farming specialists, villages and later, cities.

The decisive break came from collecting of grain, then the evolution of grain, and cereal farming. The crucial advantage of grains and cereals was that it permitted agricultural surpluses to be converted into seasonal storage. But in the early period at least, the relative calorific return from agriculture may have been less than traditional foraging and hunting, and it is not obvious that farming would have been worth the effort. Agriculture requires intense effort over long periods, often with variable results.

The capacity for storage was to prove crucial. On the one hand, grains have several useful properties. They are hard and dry, and do not readily rot and go bad. Since they are dry, they have a high calorific-to-weight ratio, making them both storable and readily transportable (Laudan 2015). But on the other hand, they are exceptionally difficult to turn into something useful and digestible. Most food gathered or caught by hunter-gatherers is eaten in its raw state or cooked over a fire, but grains require several processing and conversion stages. Wheat must be harvested, threshed, winnowed, and ground. Finally, the flour can be mixed with water and baked to produce unleavened bread. The case of wheat suggests that there must have been a strong evolutionary advantage to adopting agriculture and perhaps derive an easily storable product.

The history of salt provides another example of the importance of food storage. Salt was used since antiquity for curing foods such as beef, pork, fish, and later butter. Such was its importance that it was sometimes a strategic commodity and was used as an early form of currency (Cowen 2005).

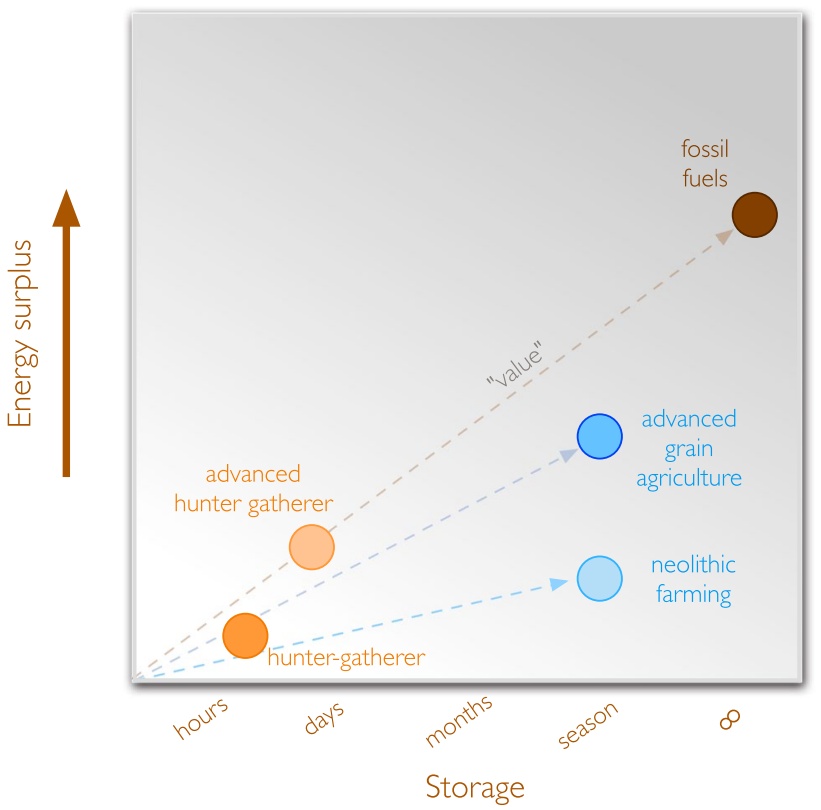

Fig. 1 Stylised graph of energy surplus versus storage. 'Value' is defined as the vector of surplus and storage 


\section{Value as the Vector of Energy Surplus and Storage}

The evolution of storage is depicted in Fig. 1 in which 'value' is defined as the vector of energy surplus and storage. The early adoption of farming may have had a lower calorific return than foraging but storage contributed to a greater vector of value than with no storage.

In the early industrial era, steam engines were extremely inefficient in converting chemical energy to mechanical motion, and the net-energy of early steam must have been remarkably low by contemporary standards. Newcomen's early engines were around 1\% efficient and Watt's early innovations lifted this to $2-4 \%$ (Buenstorf 2004). Nonetheless, as 'stored sunlight', coal was able to provide copious quantities of power on demand. Coal and steam power evolved within a virtuous cycle to leverage the power output of steam, and were to break the 'organic limit' imposed by reliance on solar energy flows (Wrigley 2010).

\section{The Role of Energy Storage}

\section{Conventional Storage}

Nearly all electrical storage to date has been pumped hydro storage (PHS), which makes up $97 \%$ or $142 \mathrm{GW}$ of global power capacity for electrical storage (United States Department of Energy (DOE) 2016). The three leading PHS countries are Japan with $26 \mathrm{GW}$, China at $24 \mathrm{GW}$, and the US at $22 \mathrm{GW}$. The Eurelectric region comprising the 34 European countries that are part of the five European synchronous regions has a total installed capacity of $35 \mathrm{GW}$. These figures relate to power but comprehensive data on storage capacity (GWh) are less readily available.

From facility-level author calculations, the storage capacity of most PHS facilities in the US, Japan, and China range from 8 to $25 \mathrm{GWh}$ per GW of installed capacity, corresponding to a typical daily arbitrage cycle with spare capacity. In Europe, the storage capacity of $2500 \mathrm{GWh}$ is dominated by Spain with $1530 \mathrm{GWh}$ in $17 \mathrm{PHS}$ plants comprising around $4.8 \mathrm{GW}$ (Pirker et al. 2011).

From Pickard (2012), the ten largest capacity facilities in the US total $13.4 \mathrm{GW}$ with $332 \mathrm{GWh}$ of storage capacity, equating to $25 \mathrm{GWh}$ per $\mathrm{GW}$. If the storage ratio is extrapolated to all 36 facilities, the storage capacity equates to $545 \mathrm{GWh}$.

PHS has historically operated in unison with coal and nuclear baseload. In the US, the deployment of PHS was relatively slow until the 1960 s, but developed in parallel with nuclear during the 1960s and 1970s, and subsequently slowed in the 1980s when nuclear deployment came to a standstill (Yang and Jackson 2011). Baseload-PHS usually operates with a daily arbitrage cycle between inflexible overnight off-peak and daytime peak. The daily cycling maximises energy throughput for a given storage capacity and underpins the economic return for PHS, while providing a demand sink for surplus off-peak baseload (Barnes and Levine 2011). Since the deregulation of electricity markets, the use of pumped hydro has expanded to cover a range of additional services, including rotational inertia, load following, frequency control, spinning reserve, and voltage regulation (MWH 2009).

At a global scale, other utility scale storage includes thermal storage (e.g. concentrated solar thermal) at $1.7 \mathrm{GW}$, which assuming $6 \mathrm{~h}$ storage equates to around $10 \mathrm{GWh}$. Other storage includes electro-mechanical (e.g. flywheel) at $1.4 \mathrm{GW}$, battery at $0.75 \mathrm{GW}$, and hydrogen at $0.003 \mathrm{GW}$ (United States Department of Energy (DOE) 2016).

\section{Connecting the Pre-Industrial with the Contemporary Role of Storage}

The question is-how to connect the pre-industrial or organic conception of surplus-storage with the role of storage within a modern electricity system? In the preindustrial context, the value of storage was in guaranteeing survival during winter or times of poor harvest. Survival during austere times was more important than feasting during good harvests-favourable harvests were valuable to the extent that food could be stored for later consumption. This aligns with a marginalist interpretation of energy supply (i.e. the first units of energy are the most valuable but there is a diminishing return to surplus energy).

In the contemporary interpretation, the guarantee of electricity supply is provided by the built infrastructure and a high 'availability factor' from a suite of generators. Modern electricity markets are founded on the concept of marginal cost pricing, in which there is always a surplus of available power. Generators with the lowest short-run marginal cost (SRMC) bid into the market first, with higher marginal cost generators providing load following.

Most of the value to residential and industrial consumers, and the cost of providing that service, is in the guaranteed connection and available power flow, rather than the cumulative energy consumption per se. For example, the electrification of the United States during the twentieth century was a major contributor to rising productivity and output (Jorgenson 1984; Schurr 1990). Much of the productivity gain from industry was a result of the 'fact of electrification' and the associated re-organisation of industrial production. In the early industrial period, the shift away from line-drive permitted organisations to adopt flexible and more efficient production processes (Rosenberg 1994). Electricity was a key enabler of innovation in industrial and consumer devices through the twentieth century. 
The value of storage is therefore proportional to the degree that storage contributes to the assurance of demanded power flow. Fortunately, the electricity supply industry has a suite of probabilistic reliability indices that fall under the broad categories of availability factor and forced outage (Billinton and Allan 1996). The availability factor defines the proportion of nameplate power that is available on demand, or in the case of VRE, the quantity of dispatchable power that is displaced (Preston 2015b).

\section{Availability Versus Capacity Factor}

The value of stored energy is evident in the availability factor versus capacity factor graph (see Fig. 2). Conventional generators convert stocks of energy into an electrical power flow. Providing the stocks are available, the energy converters (generators) can be dispatched in realtime, subject to technological and physical constraints, such as ramp-rate limits (the time rate of change of power output). In contrast, the capacity factor (often described as the full-load hours) describes the usage of the generator, and is driven mostly by the short-run marginal cost (SRMC) for dispatchable generators, or the availability of the natural flows in the case of VRE (Tasman 2009).

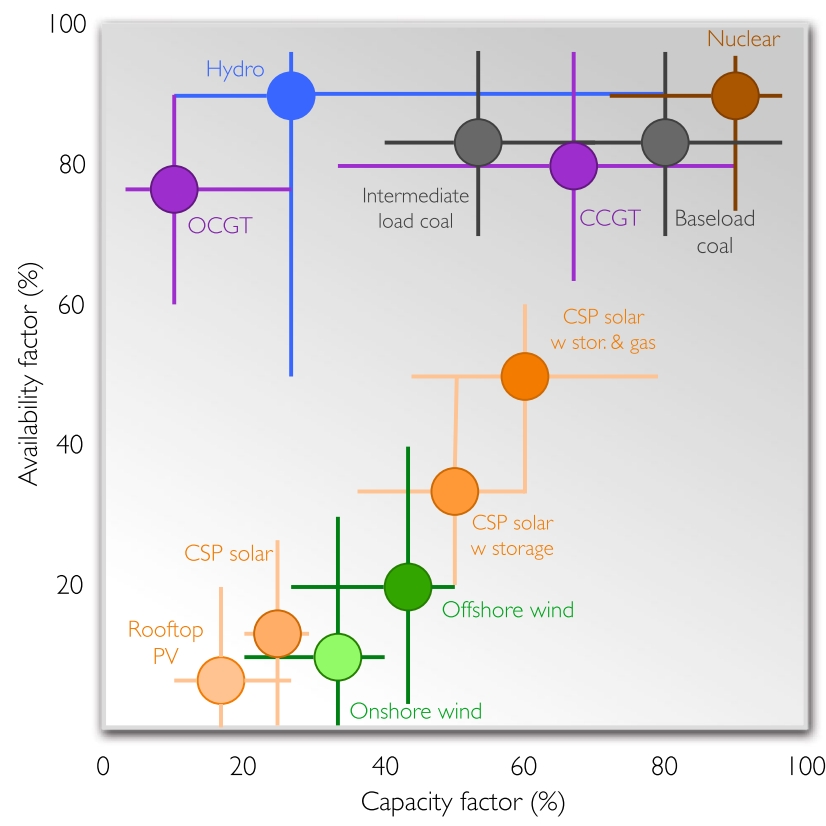

Fig. 2 Graph of capacity factor versus availability factor with typical ranges shown as whisker plots. Availability and capacity factor representative figures from Sims et al. (2011, Table 8.1), Sims et al. (2007), Bashmakov et al. (2014), Australian Energy Market Operator (AEMO) (2012, Table 6), US Energy Information Administration (EIA) (2015), International Renewable Energy Agency (IRENA) (2012, Table 1)
From the perspective of an individual generator, conventional generation can be considered to have access to unlimited fuel storage within a planning time frame (i.e. sufficient fuel at all times), and therefore possess high availability factors. In contrast, solar PV without storage has a low availability factor, except to the extent that solar insolation coincides with annual peak demand (Denholm et al. 2015). The rising availability of the various types of concentrated solar is a direct result of solar tracking, solar field multipliers, built-in storage, and natural gas backup, which are reflected in progressively higher costs (International Renewable Energy Agency (IRENA) 2012).

\section{Role for VRE Storage}

From an operational viewpoint, the purpose of storage is to increase operational flexibility. From the perspective of VRE, the role of storage is to boost the availabilitythat is, a greater proportion of the nameplate power of the VRE is considered 'firm' when power is demanded. From the perspective of large thermal generators, the role of storage is to increase utilisation during off-peak periods (see Fig. 3).

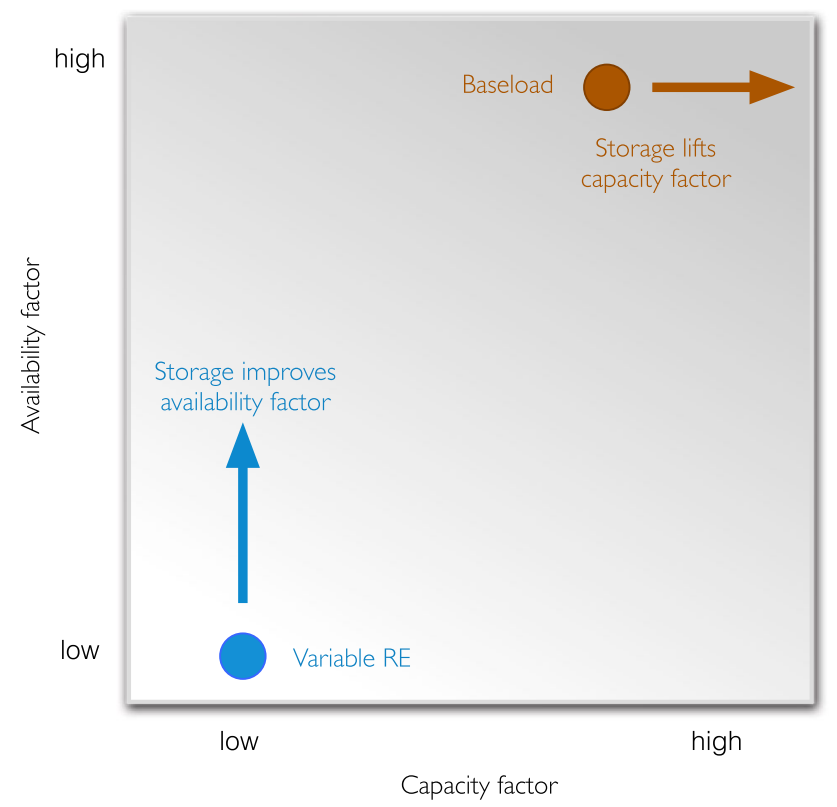

Fig. 3 Stylised effect of storage on baseload and variable renewable energy 


\section{Methods}

\section{EROI Assessments Have Focused on Net-Energy Only}

In EROI assessments, storage is rarely, if ever, explicitly incorporated. This is probably due to the universality of storage being embedded within fossil fuels - the notion of stored sunlight is simply built into the energy sources (Schramski et al. 2015). Many analyses have incorporated 'energy quality', or exergy, as a scaling factor in EROI analysis (e.g. Ayres and Warr (2010); Murphy et al. (2011)) to differentiate between the economic usefulness of energy in its various states-a megajoule of electricity is more useful than a megajoule of coal.

\section{Overview}

The proposed framework requires calculating the embodied energy of the VRE-storage sub-system relative to the displaced capacity of conventional generation. The methodology can be applied at any point along an energy transition pathway. In this context, conventional generation refers to thermal generation or hydro. The key concept is that the EROI of conventional generation substitutes should be compared against the capacity they are replacing. In contrast, the conventional abatement approach is to consider the cost of displacing fossil fuel consumption as a consequence of applying environmental taxes or regulation on energy (Enevoldsen et al. 2009).

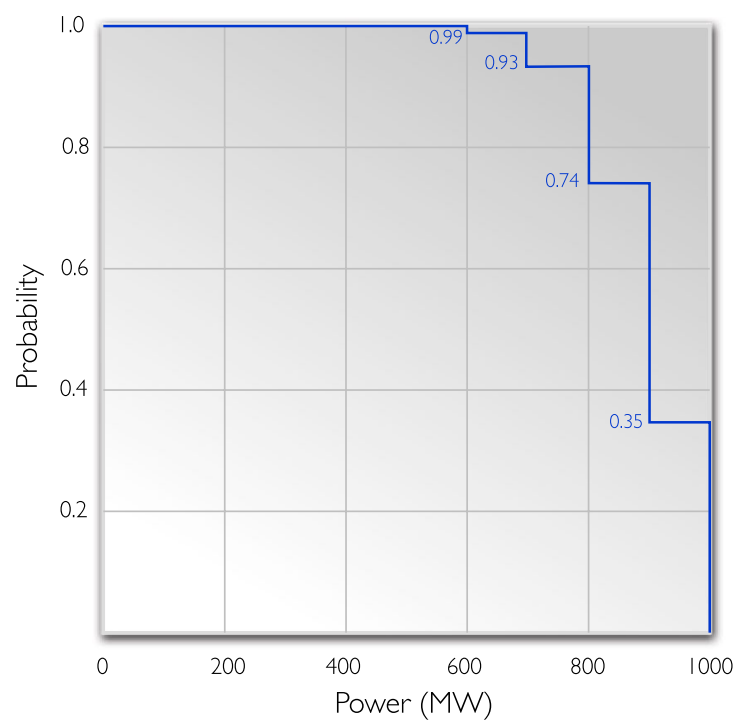

\section{Reliability Metrics for Conventional Generation}

The availability of conventional generation is approximately proportional to the inverse of the forced outage rate (Billinton and Allan 1996, chpt.11). The forced outage rate is defined as the proportion of operating time that a unit is out of service due to unexpected problems or failures. Since forced outages are usually uncorrelated between conventional generators (i.e. the distribution functions are independent random variables), the system reliability at a given power asymptotes towards $100 \%$ as additional generators are added to the system.

To illustrate this, Fig. 4 plots the cumulative density function (CDF) (left) and probability density function (PDF) of a given capacity being available in any hour for a hypothetical suite of 10 generators, each $100 \mathrm{MW}$ with a forced outage rate (FOR) of 0.1 (or equivalently, an availability of 0.9 ). An FOR of 0.1 means that there is a $10 \%$ probability of an outage in a given hour. The plot has been calculated using the recursive convolution algorithm given in Preston (2016a). The left plot indicates that there is a 93\% probability of at least $800 \mathrm{MW}$ being available. The right plot indicates that there is $19 \%$ probability of exactly $800 \mathrm{MW}$ being available. The CDF of annual demand is often referred to as the 'load duration curve'. The electricity supply industry uses many indices to describe availability, including seasonal derating factors and planned maintenance [see IEEE (2007)]. In this context, availability refers to effective availability factor (EAF) in IEEE (2007).

The PDF, such as the right side of Fig. 4, can be combined with the projected demand function, to produce a probabilistic reliability assessment for each hour. The

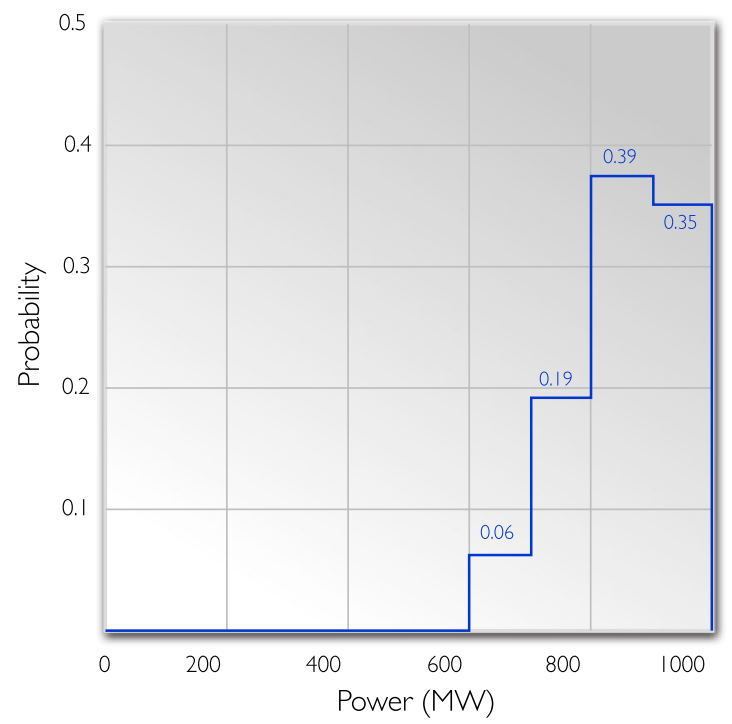

Fig. 4 Available capacity curve for 10 generators, each $100 \mathrm{MW}$, and forced outage rate (FOR) of 0.1 . Left-cumulative density function (CDF), right - probability density function (PDF) 
Fig. 5 Stylised probability density function (PDF) for Texas ERCOT system for a year. LOLE is equal to the intersection of the areas bounded by the demand and supply curves

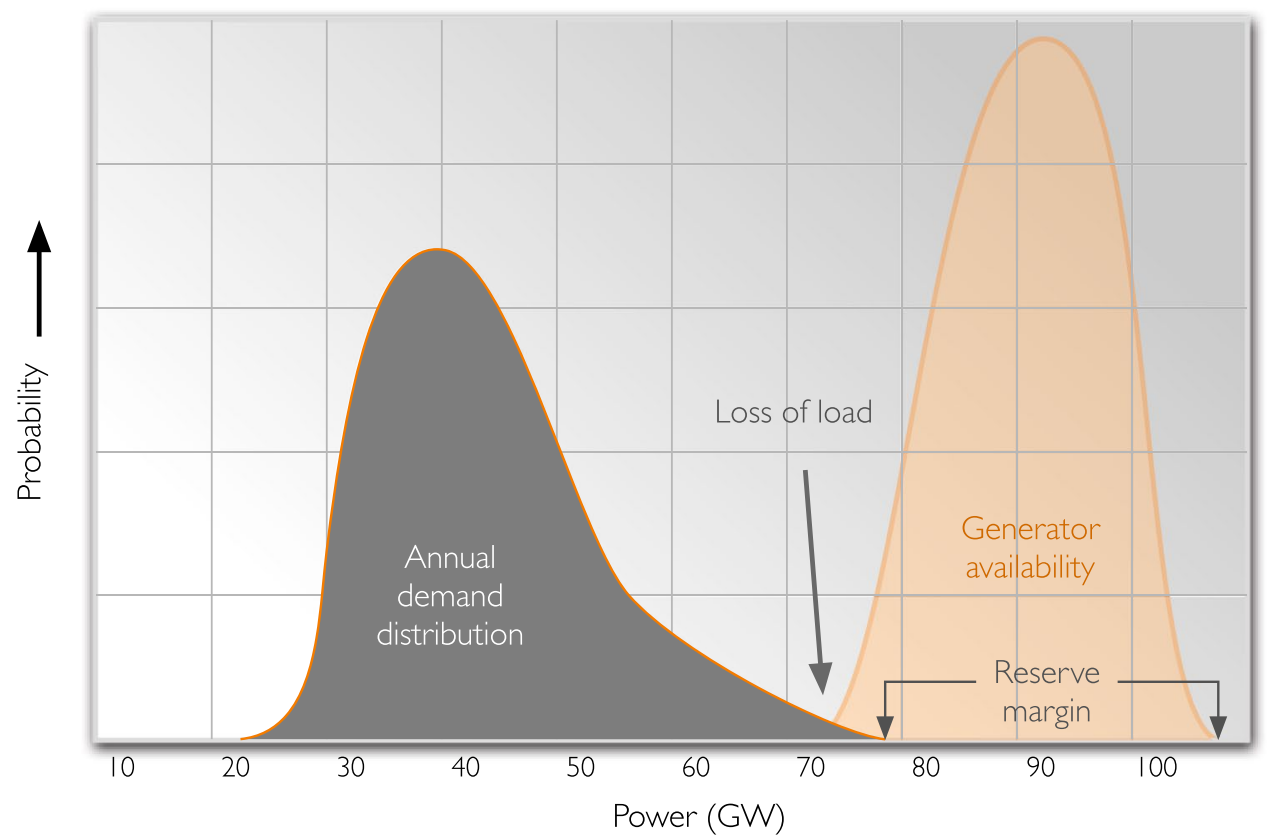

probability of demand exceeding supply for each hour is termed the loss-of-load-probability (LOLP). The LOLPs for every hour are added to give the loss-of-load-hours (LOLH) over the projected time frame (e.g. 1 year). Alternatively, the LOLP for the peak hour only for each day can be added to give the loss-of-load-expectation (LOLE). There may be slight differences in methodology across regional operators. For example, LOLE can be expressed as either days/year, or hours/year (OFGEM 2013). An alternative energy-based metric is the expected unserved energy (EUE), which is the sum of the unserved energy over all hours in a year.

Figure 5 illustrates this graphically for a stylised example of the Texas ERCOT grid over a year. The intersection of the areas bounded by the demand and supply curves gives the probabilistic LOLH. Note that this does not imply that demand will exceed supply but that there is a small but finite probability of unmet demand.

Since surplus generator capacity is costly, and outages are also costly, the optimal arrangement is to install only as much capacity as is required to provide a given (small) probability of unmet demand. In economics terminology, this can be framed as the intersection of the reliability-cost and reliability-worth curves (Billinton and Allan 1996, Fig. 1.3).

The standard criteria for generator reserve margin planning vary between jurisdictions. The United States standard is a LOLE of 'one day in ten years' (North American Electric Reliability Corporation (NERC) 2011). The 'one day in ten years' means that an outage (of any duration) should only occur on one day in 10 years on average. For comparison, a LOLE of $2.9 h$ per year is used within the reliability standards used by France, Ireland, and Belgium (OFGEM 2013). Australia applies an EUE standard of $0.002 \%$ of annual consumption (Australian Energy Market Operator (AEMO) 2013, Table 1). In this context, 'outage' refers to the adequacy of the bulk system and excludes outages due to local network interruptions due to storms etc.

\section{The Analysed System}

\section{Reliability of Variable Renewable Generation}

Renewable converters (e.g. solar panels, wind turbines) convert natural flows into electrical power flows, but have limited capability of controlling power on demand (although turning down is an obvious mode of control). Since renewable converters within a region are highly correlated (i.e. it is sunny or relatively windy everywhere), VRE cannot be modelled as random independent variables using a convolution algorithm. Instead, they must be modelled as load reducers (Preston 2015b). The distinction between 'adding to supply' and 'subtracting from demand' may appear subtle, but is important because the value of VRE depends on both the supply and demand functions. VRE can be conceptualised as changing the shape of the PDF of demand (left side of Fig. 5). The degree to which VRE changes the LOLE is related to the degree that the rightward tail of the distribution is shifted leftward (i.e. the reliability value of VRE is dominated by the co-incidence of VRE with annual peak loads).

The first units of wind (or solar) produce the highest availability factor, with additional wind power subject to 
diminishing returns. The reason for this is that if the first units of wind reduce peak loads, those hours are no longer peak hours, and the system reliability is dominated by other load hours not well served by wind (Preston 2015b). Therefore additional wind during those (now) non-peak hours reduces net-demand but does not contribute further to peak demand mitigation. This general property applies regardless of the composition of the grid. The sub-system of interest could also be composed of multiple VRE types (e.g. wind + solar PV), which would yield a composite density function.

Therefore, the availability of a suite of VRE is defined as the reduction in net-demand as a proportion of nameplate capacity, at a given probabilistic reliability. For example, if $100 \mathrm{MW}$ of wind power permits an additional $10 \mathrm{MW}$ of demand at a given reliability level, the availability is expressed as $10 \%$ or $10 \mathrm{MW}$.

\section{Charging Storage with VRE Overbuild}

A key question is the quantity of storage and the VRE overbuild that is required to substitute for generation over and above inflexible or baseload generation. Storage must be accompanied by VRE overbuild in order to charge stores. Overbuild is defined as capacity that is surplus to demand-it can be defined at both a local or system level. For example, at a household level, rooftop solar that produces surplus solar power could be either stored locally or exported into the grid. At a system level, wind power that exceeds a given usable proportion of system supply could be exported to an adjoining grid, stored, or curtailed (Denholm and Hand 2011).

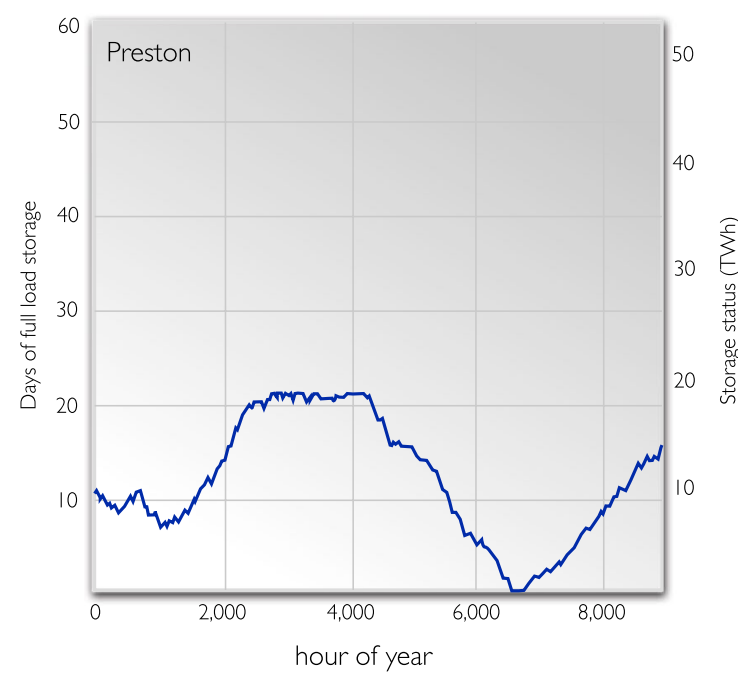

\section{Marginal Returns to Storage}

The first units of storage and overbuild are the most useful. The reason is that the PDF (i.e. the histogram describing the number of annual hours for each 'bin' of power) for typical electricity systems is approximately bell shaped with a tail extending rightward representing short duration peak loads (see Fig. 5). Therefore a relatively modest quantity of storage can shift the PDF of generator availability leftward (right side of Fig. 5), 'filling' the highest peak loads that make up the rightward tail of the demand distribution. These peak loads are often the most valuable and easiest to fill, particular if the peaks tend to correlate with VRE power (e.g. solar power and air conditioning). However, progressively greater amounts of energy must be used to fill the (new) peaks after the first peaks are filled. The marginal returns to storage aligns with market-based estimates of the value of storage [e.g. McConnell et al. (2015)] and net-energy-based assessments [e.g. Barnhart and Benson (2013)].

\section{ERCOT Regional Grid}

The framework will be applied to a suite of renewable simulations from Preston (2015a, 2016b), with reliability methodology described in detail in Preston et al. (1997), a simplified procedure in Preston (2015b) and detailed output files at http://egpreston.com/cases.htm. The simulations are for the Texas ERCOT network. ERCOT is one of nine independent system operators (ISO) in the US. It supplies electric power to around 24 million Texas customers. The ERCOT region has abundant wind and solar resources.

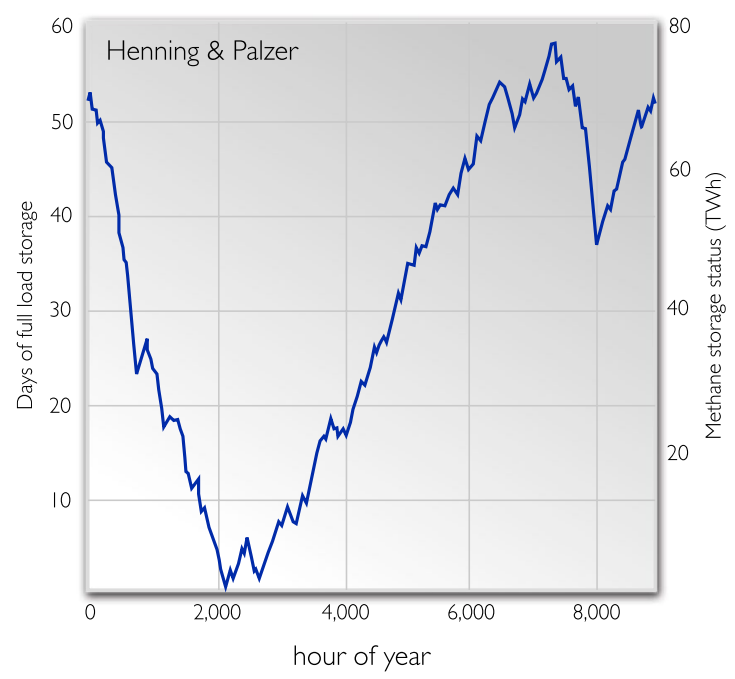

Fig. 6 Storage status for Preston simulation (left) for 1 Jan 2010-31 Dec 2010 and Henning and Palzer (2014, Fig. 4.5) gas storage (right). Normalised as days of full-load storage, based on annual average load 
The Preston simulations were modelled as time-series, demand-balance simulations using Fortran, optimised for least cost but constrained to VRE plus electrical storage, with a further reliability constraint (LOLE). Since the simulations were modelled with higher cost seasonal storage, they are not intended as a comprehensive costoptimised solution to high-penetration VRE. Indeed, commercially available electrical storage is economic only for storage up to several hours (Luo et al. 2015, Table 12). Since this study is concerned with VRE plus storage, they provide a valuable tool to establish reference points to demonstrate the framework. Furthermore, the magnitude of seasonal storage (of any type) at highVRE penetration is consistent with the published scenario literature in relation to the days of full-load storage required (see "Storage requirements" Section and Fig. 6).

The simulations provide a base case, two intermediate steps, and a $100 \%$ renewable simulation (see Table 1). They are based on projected demand in 2017, using historical wind and solar data from NREL, and hourly loads from 2010 to 2012. Wind and solar data were derived from NREL datasets. Wind was located along the coast, Panhandle, and west Texas. Solar sites included central Texas (Austin), south central Texas (San Antonio), and west Texas (Pecos). They are optimised for the US standard LOLE of 0.1. The intermediate steps and LOLE fit readily into the proposed framework, and provide multiple reference points for establishing framework parameters.

Preston has started with the incumbent ERCOT system, assumed zero wind power, but with $76 \mathrm{GW}$ of fossil thermal generation and $5.15 \mathrm{GW}$ of nuclear power (see Table 1). Each of the simulations traced 3 consecutive years with a maximum demand of around $71 \mathrm{GW}$ and minimum $28 \mathrm{GW}$. Annual energy consumption is around $340 \mathrm{TWh}$. Additional wind and solar PV was added, while thermal generation was reduced, to maintain a LOLE of 0.1. Hence, the VRE has replaced the installed capacity of thermal plant at the given system reliability level. Nextly, storage was added while reducing thermal generation to also maintain a LOLE of 0.1 . Figure 6 (left) displays the storage status for 2010 for the full year of the simulation. The right side is derived from Henning and Palzer (2014) as a comparison. In both cases, the requirement for seasonal storage is evident.

\section{Embodied Energy of VRE and Storage}

Embodied energy has been calculated for two storage types for comparison: PHS and Li-ion. These have been selected to provide low and high embodied energy references for commercially mature storage devices. PHS is the dominant form of electrical storage globally, providing a valuable reference for a near lower bound for embodied energy and high round-trip efficiency. Li-ion is projected to expand and provides a distributed generation reference. In practice, PHS is not a large-scale option in Texas-Hall and Lee (2014) identified several possible PHS projects in Texas but these were relatively small. Compressed air energy storage (CAES) possesses intermediate embodied energy (Denholm and Kulcinski 2004). Power-to-gas combined with gas turbine is a potential future seasonal storage option (Schiebahn et al. 2015), which could be assessed with the proposed framework.

In this study, embodied energy for storage is defined as the embodied energy per unit of storage (MJ per $\mathrm{kWh}$ of storage). There are uncertainties with Li-ion embodied energy, which is largely related to accessing firm-level energy consumption and production data. Furthermore, nearly all battery life-cycle assessments are carried out as process-based attributional assessments, which understate embodied energy relative to systematically complete hybrid assessments [see Crawford (2009)].

This study uses data from Ellingsen et al. (2014), and is based on primary data for a traction battery cell. Ellingsen's medium 'ASV' value of $960 \mathrm{MJ} / \mathrm{kWh}$ was used, which is representative of the broader literature [e.g. Zackrisson et al. (2010) $790 \mathrm{MJ} / \mathrm{kWh}$, Rydh and Sandén (2005, Table 6) $1510-1870 \mathrm{MJ} / \mathrm{kWh}$ for recycled and virgin materials, respectively]. The current learning rate (the cost reduction following a cumulative doubling of production) of vehicle battery packs using Li-ion is 6-9\% (Nykvist and Nilsson 2015). Barnhart and Benson (2013) explored the theoretical
Table 1 Reference VRE plus storage model from Preston (2015a)

\begin{tabular}{llllcrc}
\hline Scenario & Wind (GW) & $\begin{array}{l}\text { Solar PV } \\
(\mathrm{GW})\end{array}$ & Storage $(\mathrm{GW})$ & Storage (GWh) & Fossil & Nuclear \\
\hline $\begin{array}{l}\text { Actual installed } \\
\text { capacity at Dec }\end{array}$ & 16 & 0.3 & 0 & 0 & 72 & 5.15 \\
$\quad 2015$ & & & & & & \\
Reference & 0 & 0 & 0 & 0 & 76 & 5.15 \\
Case 4 & 24 & 24 & 0 & 0 & 63 & 5.15 \\
Case 6 & 68 & 76 & 50 & 16,500 & 0 & 5.15 \\
Case 7 & 76 & 84 & 54 & 18,970 & 0 & 0 \\
\hline
\end{tabular}


Table 2 Assumptions applied to embodied energy calculation for Texas

\begin{tabular}{lllll}
\hline & Wind & Solar PV & PHS storage & Li-ion storage \\
\hline Capacity factor & $40 \%$ & $18.7 \%[1]$ & N/A & N/A \\
Embodied energy & $10,512 \mathrm{MJ} / \mathrm{kW}[8]$ & $5911 \mathrm{MJ} / \mathrm{kW}[9]$ & $400 \mathrm{MJ} / \mathrm{kWh}[2]$ & $960 \mathrm{MJ} / \mathrm{kWh} \mathrm{[3]}$ \\
Modelled lifetime & 25 years [4] & 30 years [5] & 50 years [6] & 10 years [7] \\
Lifetime EROI of VRE only & $30: 1[8]$ & $25: 1[9]$ & N/A & N/A \\
Annual energy production & $3504 \mathrm{kWh} / \mathrm{kW}$ & $1752 \mathrm{kWh} / \mathrm{kW}$ & N/A & N/A \\
\hline
\end{tabular}

[1] Representative figure derived from global horizontal irradiance averaged between Austin and El Paso (The University of Texas at Austin 2016) [2] (Denholm and Kulcinski 2004) [3] (Ellingsen et al. 2014), use 'ASV' value [4] (Kubiszewski et al. 2010) meta-review ranged 15-30 years, most were 20 years, assume 25 [5] most studies assume 25 or 30 years, assume 30 years [6] assume 50+ years [7] Li-ion is cycled limited, cycle life is dependent on depth-of-discharge and capacity degrades with cycling, assume 10 years as highend estimate for warranties [8] Kubiszewski et al. (2010) estimated EROI of 19.8-25.2 in 2009, assume improvement to 30:1. Embodied energy calculated from EROI data [9] taken as a high-end estimate from Dale and Benson (2013). Embodied energy calculated from EROI data
Table 3 Aggregate embodied energy over 50-year time frame

\begin{tabular}{|c|c|c|c|c|}
\hline & \multicolumn{2}{|c|}{$\begin{array}{l}\text { 50-year VRE embodied energy } \\
\text { (PJ) }\end{array}$} & \multicolumn{2}{|c|}{$\begin{array}{l}50 \text {-year storage } \\
\text { embodied energy } \\
(\mathrm{PJ})\end{array}$} \\
\hline & Wind & Solar PV & PHS & Li-ion \\
\hline Case 4 & 505 & 227 & 0 & 0 \\
\hline Case 6 & 1430 & 718 & 6583 & 79,200 \\
\hline Case 7 & 1598 & 794 & 7569 & 91,056 \\
\hline
\end{tabular}

Table 4 Summary of 100\% VRE with storage based on simulation model for $76 \mathrm{GW}$ wind, $84 \mathrm{GW}$ solar PV, $54 \mathrm{GW}$, and 18,970 GWh storage, for two types of storage, pumped hydro storage and lithiumion

\begin{tabular}{llllll}
\hline & \multicolumn{2}{l}{$\begin{array}{l}\text { 50-year embodied energy of } \\
\text { VRE + storage (PJ) }\end{array}$} & & \multicolumn{2}{l}{$\begin{array}{l}\text { 50-year EROI of } \\
\text { VRE+storage }\end{array}$} \\
\cline { 2 - 3 } \cline { 5 - 6 } & PHS & Li-ion & & PHS & Li-ion \\
\hline Case 7 & 9961 & 93,448 & & $7.2: 1$ & $0.8: 1$ \\
\hline
\end{tabular}

and resource constraints of battery manufacture and concluded that embodied energy of batteries could be reduced 'at most by a factor 2 to 3', but also note that the greatest potential for reducing the per-cycle embodied energy lies in increasing the cycle life (Barnhart and Benson 2013, Sect. 3.3). The recyclability of Li-ion packs is constrained by the complexity of cell and battery construction, and diffusion of elements throughout the anode, cathode, and electrolyte (Gaines 2014). Therefore the energetic benefit of recycling Li-ion chemistry is relatively low (Rydh and Sandén 2005, Fig. 4). Repurposing of EV battery pack cells for grid storage to extend their service life has also been proposed, with as yet uncertain commercial value (Neubauer et al. 2012). The repurposing has been described as 'cascading reuse' in the life-cycle literature, and requires allocating the environmental burden across multiple uses. Various procedures have been proposed for allocation, including 'quality based', 'cut-off', and '50/50' (Richa et al. 2015). The use of vehicle-to-grid storage would similarly entail allocation across multiple uses.

The embodied energy for PHS of $400 \mathrm{MJ} / \mathrm{kWh}$ is taken from Denholm and Kulcinski (2004). PHS is a mature civil engineering technology and therefore not subject to a projected significant decline in embodied energy. An advantage of PHS is its long life of 60 years or greater.

The embodied energy for wind and solar PV were calculated from the respective assumed EROI data as shown in Table 2. For wind, a meta-review by Kubiszewski et al. (2010) estimated 19.8-25.2 in 2009. Since wind has progressed in recent years, this study assumes 30:1. For solar PV, Raugei et al. (2012) calculated 5.9-11.8 for data from 2009 to 2011. Since solar PV has progressed significantly in recent years, this study takes a high-end estimate of around 25 from a review from Dale and Benson (2013). A sensitivity analysis was included with varying EROI for the wind and solar PV, with wind from 20:1 to 40:1 and solar PV from 15:1 to 40:1.

The embodied energy and resulting EROI are shown in Tables 3 and 4. In this work, the EROI is defined for the VRE-storage sub-system-EROI is not defined for storage as a stand-alone unit. EROI VRE-storage is equal to the ratio of the gross lifetime energy supplied by the subsystem $E_{g}$, and the sum of the lifetime embodied energy of the VRE, $E$ VRE and storage, $E_{\text {storage }}$. The lifetime of the subsystem has been defined as 50 years. The benefit of applying this methodology is that it is possible to trade-off the energetic costs of storage with the value that storage provides, with different grid mixes, VRE penetration, and geographic regions.

$E R O I_{V R E+\text { storage }}=\frac{E_{g}}{E_{V R E}+E_{\text {storage }}}$ 


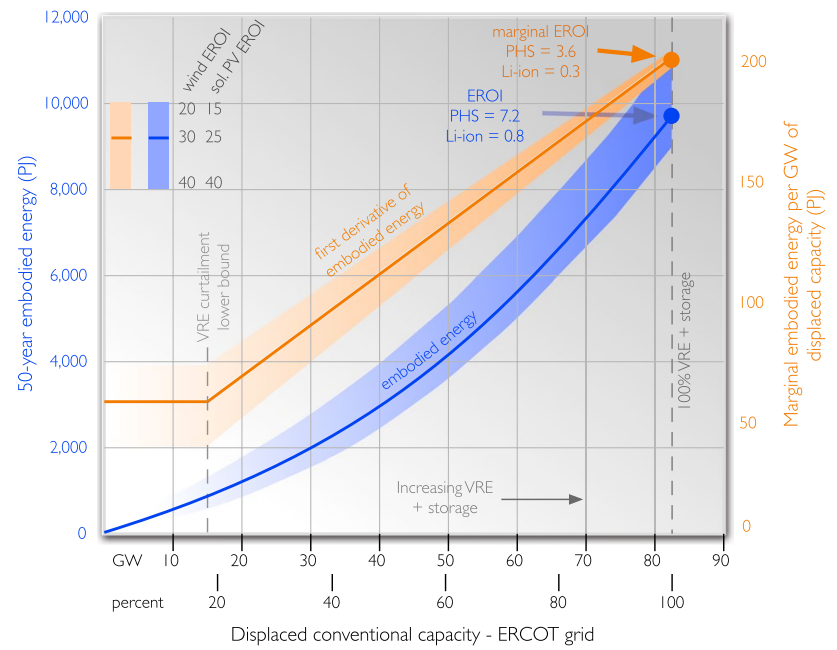

Fig. 7 Embodied energy of VRE plus storage for PHS for ERCOT grid, displaced generation based on simulation by Preston (2015a)

\section{Results and Discussion}

\section{Overview}

Figure 7 depicts the embodied energy and marginal embodied energy for the generalised case with pumped hydro storage. Referring to the figure, the embodied energy (blue curve) below 14 GW (curtailment lower bound) was calculated from Preston case 4 (zero storage) and assumed to be linear up to $14 \mathrm{GW}$. For greater than $14 \mathrm{GW}$, a trend curve was estimated from the method of least squares, applied to a second-order polynomial. The second-order polynomial was selected as the closest fit based on previous work with off-grid solar PV and storage (Palmer 2013). The $\mathrm{R}^{2}$ correlation was 0.9997 . The solid curves are for an assumed EROI for wind of 30 and solar PV of 25 (see from Table 2). The shaded areas bounding the solid lines show sensitivity for varying wind and solar EROI, from wind at 20 and solar at 15 , up to wind at 40 and solar at 40.

From the first derivative of the embodied energy curve, it is possible to estimate the marginal embodied energy, and from this, the marginal EROI. The marginal EROI refers to the $E R O I_{V R E-s t o r a g e}$ of the additional VRE storage required to provide an additional gigawatt of displaced capacity. Importantly, the marginal EROI varies depending on the penetration of VRE. Since the trend was assumed a secondorder polynomial, the first derivative is necessarily linear.

As shown in Fig. 7, the marginal embodied energy per unit of displaced capacity is around four times higher at the high end-point of the line for PHS, but around 41-fold for Li-ion (not shown in graph). This implies that it is 4 to 41 times (PHS versus Li-ion) more energetically expensive to displace a gigawatt of conventional capacity at near- $100 \%$ VRE versus low penetration VRE.
The sensitivity shows that the EROI of the wind and solar is much less important at high penetration since the embodied energy is dominated by the storage. This aligns with other studies that suggest it may be energetically preferable to curtail renewable energy at times, rather than store energy [e.g. Barnhart et al. (2013)].

\section{The Embodied Energy and Marginal Embodied Energy Curves}

From this work, the most important outcome is the shape and behaviour of the embodied energy and marginal embodied energy curves. The first units of VRE and storage have the lowest embodied energy (and therefore highest EROI). This implies that the first hour of storage produces

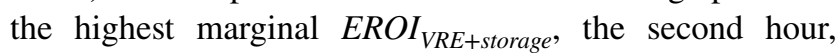
less so, and so on. Conceptually, VRE changes the shape of the 'demand distribution' density function (Fig. 5), and storage shifts the 'generator availability' density function rightward.

The ERCOT simulation is intended to demonstrate the framework, but different regional grids, assumptions, and simulations would provide different results. Furthermore, ERCOT is a single region in the US, and the simulation is not seeking to capture the benefits of geographic diversity. However, the qualitative relationships would be expected to be broadly similar-all large grids exhibit a similarly shaped load duration curve [e.g. Billinton and Allan (1996, Fig. 2.4)] giving the characteristic PDF shown in Fig. 5. Demand management technologies that address peak demand effectively 'blunt' the rightward tail of the 'annual demand distribution' (Fig. 5), shifting the right-hand tail leftwards.

Wind and solar PV exhibit broadly similar shaped CDF curves across different regions, shown in the bottom section of Fig. 8. The parameters and size will vary depending on geographic location but the characteristic shape will be similar.

\section{Key Differences Between VRE-Storage and Conventional Generation}

There are two key differences between a VRE-storage system and a suite of conventional generators. In the case of conventional generation, the risk of outage between generators is mostly uncorrelated. Therefore each generator can be treated as a random independent variable, cumulatively adding to system available capacity. In contrast, VRE of a particular type is highly correlated within a region, limiting the available firm capacity. Technology diversity and geographic dispersion are two methods to de-correlate VRE availability. 

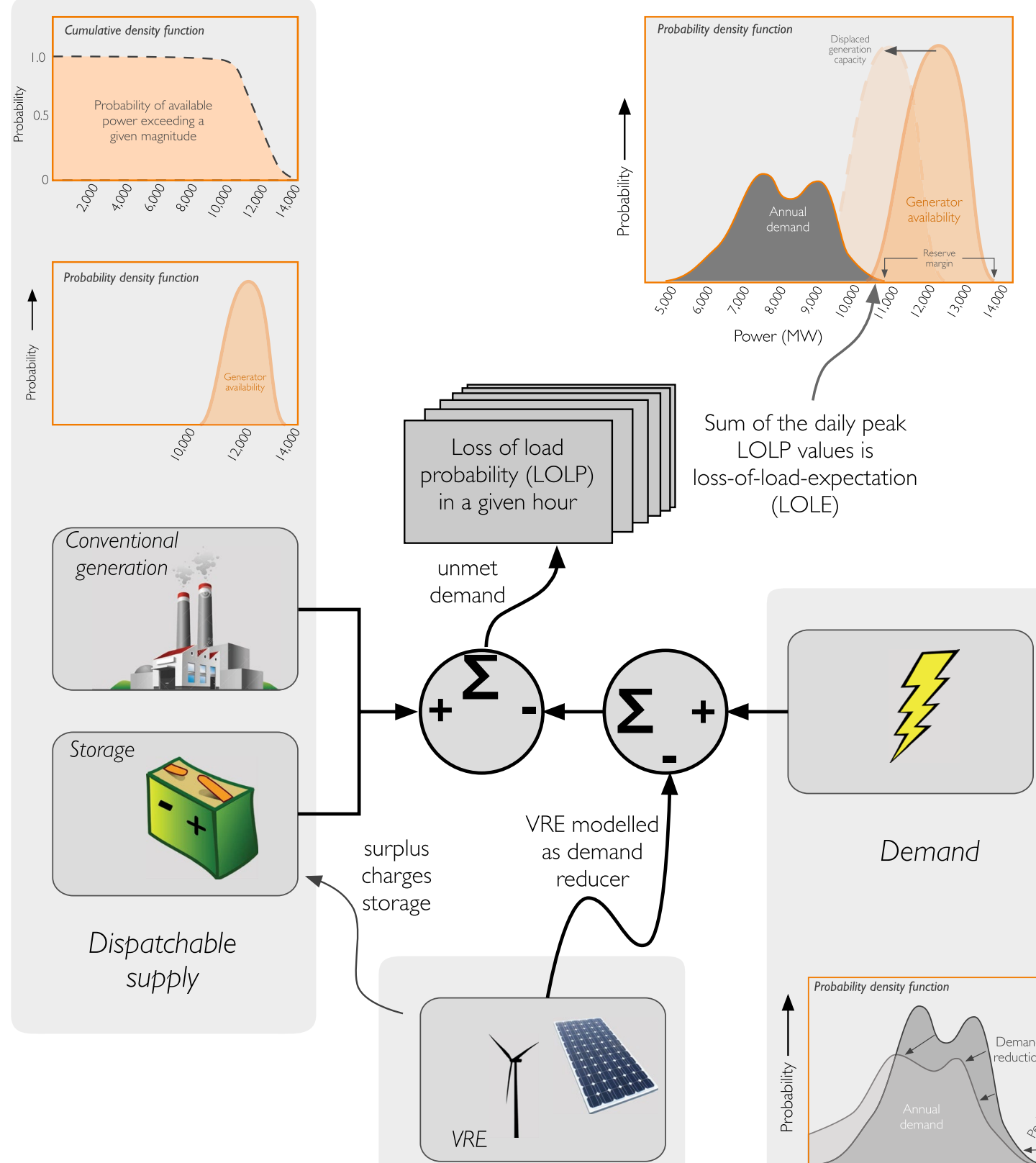

Demand

Dispatchable supply

\section{Non-dispatchable} supply
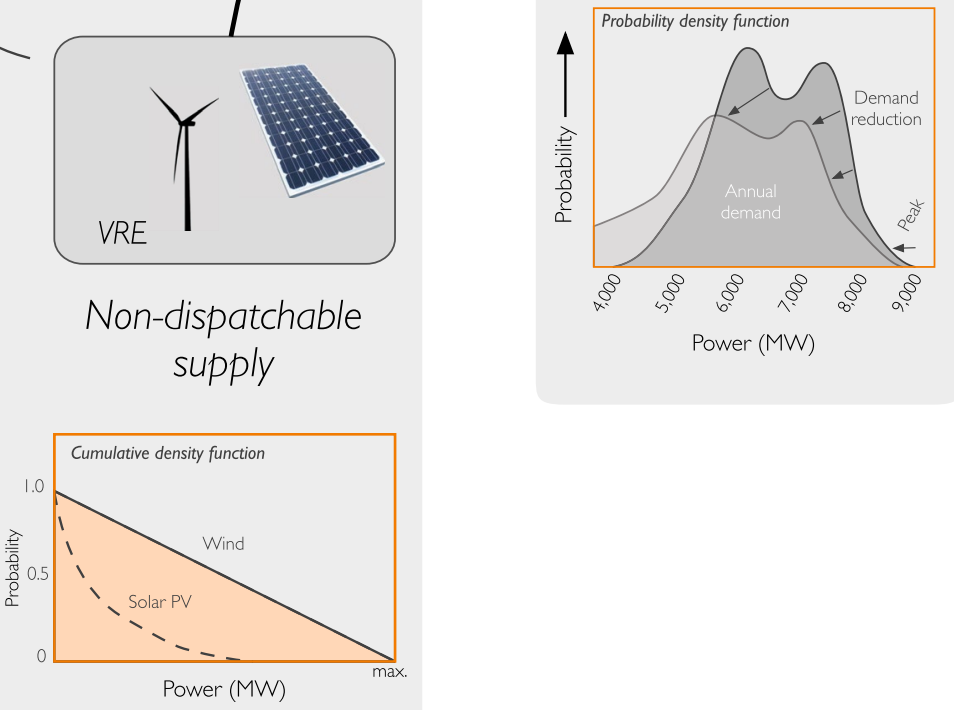

Fig. 8 Stylised representation of reliability measurement for system composed of conventional generation, VRE, and storage 
Nextly, conventional generation can be considered to have unlimited storage available from the perspective of an individual generator within a planning time frame. VRE does not have access to storage except through discrete storage devices. The devices can only be charged through overbuilding VRE capacity to produce a surplus at times of high wind speeds or solar irradiation.

\section{Consequence of Diminishing Returns}

Rising VRE penetration is subject to diminishing returns such that the marginal EROI may fall below the minimum useful EROI for society. Hall et al. (2009) identifies an EROI of around 3:1 as being the absolute lowest useful EROI for oil or corn-based ethanol to provide unsubsidised energy to society, but an EROI of 10:1 being required to deliver unsubsidised energy for a modern developed society. Lambert et al. (2014) suggest a societal EROI of 20-30:1 as being necessary for a high standard of living.

A shift from an electrical system based mostly on energy stocks to one based mostly on natural flows is handicapped by the energetic demands of surplus VRE and storage. From this case study, it is readily apparent that Li-ion batteries could only usefully contribute a short-term role to buffering VRE. However, the energetic requirements of PHS are sufficiently low to enable a greater penetration of VRE. Future storage devices may be energetically superior to PHS.

\section{0\% VRE Scenarios}

In a prospective $100 \%$ VRE scenario, it is not necessary to consider the displaced capacity as shown in Fig. 7 since it is assumed that there is zero fossil fuel capacity. The system-wide $E R O I_{\text {system }}$ is calculated as a standalone estimate for the given probabilistic reliability (e.g. $\mathrm{LOLE}=0.1$ ) as shown in Eq. 3, where EROI $I_{\text {system }}$ is the ratio of the gross lifetime energy supplied by the entire system $E_{g}$, and the sum of the lifetime embodied energy of the VRE, $E_{V R E}$ and storage, $E_{\text {storage }}$.

$$
E R O I_{\text {system }}=\frac{E_{g}}{E_{V R E}+E_{\text {storage }}}
$$

Similarly, in scenarios that retain conventional capacity (e.g. hydro), the methodology can be used to assess the $E R O I_{V R E-s t o r a g e}$ of the non-conventional portion. Since demand-balance simulations in the academic literature are usually modelled without probabilistic reliability, it may be challenging to compare alternative scenarios on a like-forlike basis. Rigorous application of the methodology will require the incorporation of loss-of-load estimates into scenario models.
In much the same way as scenarios can be compared based on cost (e.g. total system cost or $\$ / \mathrm{kWh}$ ), they can be compared for system-wide EROI. A high EROI estimate would imply that the system is energetically viable from a net-energy perspective, and therefore capable of converting natural energy flows into demand-based electricity. A low EROI estimate $(<10: 1)$ would imply that the system is not energetically viable without access to an external source of inexpensive energy (i.e. the system is only energetically viable due to the importation of components from regions with inexpensive energy).

\section{Availability of Storage}

This study makes no assumptions about the prospective availability of storage. To put the scale of the PHS into perspective, the US is the third leading country in pumped hydro storage, with an estimated $547 \mathrm{GWh}$ of storage capacity, and Preston's 100\% VRE ERCOT scenario requires $18,970 \mathrm{GWh}$ of storage. ERCOT (340 TWh) represents around $9 \%$ of total annual US electrical generation (3764 TWh).

The methane or hydrogen storage option, via the powerto-gas and gas turbine pathways described in Palzer and Henning (2014), offers another prospective long-term pathway with as yet uncertain costs (Götz et al. 2016; Sterner 2009) and embodied energy. The high energy density of methane, stored either within pipelines, underground storage, or as liquefied LNG, potentially offers seasonal storage. For example, it has been estimated that the storage capacity of the German gas network is of the order of 'hundreds of TWh' (i.e. >300,000 GWh) (Sterner 2009, p. 105). The use of existing gas infrastructure would be favourable from a net-energy perspective. Götz et al. (2016) details the various technical and economic barriers that would need to be resolved for successful commercialisation, including the availability of $\mathrm{CO}_{2}$ sources, the dynamic behaviour of the various processes, a low round-trip efficiency, and high capital cost.

\section{Conclusions}

It was argued that energy storage, along with net-energy, is a fundamental property of the useful energy available to society, and can be described by the vector of surplus energy and storage. The examples of the development of agriculture, especially grains, provide an example of the value of storage. Despite the relatively high energetic demand of early agriculture, grains provided calories when they were needed-access to food during austere times was more important than feasting during good harvests. The early Industrial Revolution provides a similar lesson. 
Early coal-fired steam was extremely inefficient and energetically expensive but gave access to essentially unlimited 'stored sunlight', providing copious quantities of power on demand.

These historic lessons inform a methodology for evaluating the value of variable renewable energy and storage in a modern context. The methodology is based on the EROI metric, which gives greater weight to the principles of energetics over market prices.

Much of the contemporary global shift to variable renewable energy is adding to the capital stock rather than substituting away from legacy infrastructure. This could be contrasted with earlier transitions in which the substituting energy source replaced legacy infrastructure and enhanced productivity. The case of coal substituting for wood, and oil for coal provides early examples. However, it may not be necessary to completely substitute to provide value. The addition of VRE to existing electrical grids reduces the fossil fuel that would otherwise have been consumed, thereby providing emission abatement, usually measured as the marginal abatement cost in \$/tonne CO2Eq.

This study argues that a long-run transition is better measured by substitution of generation capacity. Through the use of demand-balance simulations and probabilistic reliability assessments, the embodied energy of alternative VRE-storage options can be plotted against displaced generation to compare their efficacy in substituting for capacity. In a 100\% VRE scenario, the system-wide EROI is calculated as a stand-alone estimate. The most important conclusion is that rising VRE and storage exhibit marked diminishing returns, and therefore the first units of storage are the least energetically expensive. Unlike conventional generation, which has access to essentially unlimited storage in the form of fuels, VRE is handicapped by the energetic demands of surplus VRE and storage.

The rate of diminishing returns is dominated by the embodied energy of the storage device. Pumped hydro storage is currently the dominant form of electrical storage, and gives a much shallower diminishing return than Li-ion. It is apparent that the EROI of a system reliant on Li-ion (and other similar electro-chemical storage devices) would rapidly fall below the minimum useful EROI for society. In principle, if regional topography and water availability permitted, the large-scale use of pumped hydro storage would permit VRE to displace a substantial proportion of conventional generation capacity. Since electrical storage is not currently economic for seasonal storage, the scenario literature adopts lower cost strategies, such as demand management, maintaining a significant share of conventional capacity, or assuming the ready availability of large-scale biomass. In the future, other storage options may emerge, such as methane via the power-to-gas and gas turbine pathways.
The goal of this study was to introduce a framework for exploring the role of storage with net-energy and stimulate further research. Further work should include renewable simulations across different regions that are tailored to netenergy analysis and loss-of-load reliability metrics.

Acknowledgements The author would like to thank Roger Dargaville of the Melbourne Energy Institute at the University of Melbourne for valuable comments and feedback. Thanks also to the anonymous reviewers for their valuable comments that substantially improved the paper.

\section{Compliance with Ethical Standards}

Conflict of interest The author declares no conflict of interest.

\section{References}

Abdulla K, Wirth A, Halgamuge SK, Steer KC (2014) 'Selecting an optimal combination of storage \& transmission assets with a non-dispatchable electricity supply', in Information and Automation for Sustainability (ICIAfS), 2014 7th International Conference on, pp. 1-6

ACIL Tasman (2009), Fuel resource, new entry and generation costs in the NEM, 0419-0035. AEMO, Melbourne

Aghahosseini A, Bogdanov D, Breyer C (2016) '100\% Renewable Energy in North America and the role of Solar Photovoltaics', in EU-PVSEC conference June 20-24, 7DV.4.8, Munich

Archer CL, Jacobson MZ (2007) 'Supplying baseload power and reducing transmission requirements by interconnecting wind farms'. J Appl Meteorol Climatol 46(11):1701-1717

Australian Energy Market Operator (AEMO) (2012) '2012 Planning Studies Input Tables', viewed 20 Oct 2015. https://www.aemo.com.au/media/Files/Other/planning/ Modelling_Assumptions_and_Data_2012_v3.xls

Australian Energy Market Operator (AEMO) (2013) Power system adequacy for the national electricity market. AEMO, Melbourne. https://www.aemo.com.au/media/Files/Other/electricityops/Power_System_Adequacy-Two_Year_Outlook_2013.pdf. pdf

Australian Productivity Commission (2013) Electricity network regulatory frameworks report. Productivity Commission, Canberra, http://www.pc.gov.au/inquiries/completed/electricity/report

Ayres RU, Warr B (2010) The economic growth engine: how energy and work drive material prosperity. Edward Elgar Publishing Limited, Cheltenham

Barnes FS, Levine JG (2011) Large energy storage systems handbook. CRC Press, Boca Raton

Barnhart CJ, Benson SM (2013) 'On the importance of reducing the energetic and material demands of electrical energy storage'. Energy Environ Sci 6(4):1083-1092

Barnhart CJ, Dale M, Brandt AR, Benson SM (2013) 'The energetic implications of curtailing versus storing solar-and wind-generated electricity'. Energy Environ Sci 6(10):2804-2810

Barnhart C, Carbajales-Dale M, Benson SM (2015) 'Flexible Power Grid Resources - an NEA Analysis', viewed 1 Sep 2015. Stanford University Global Climate and Energy Project. http://gcep. stanford.edu/pdfs/events/workshops/Barnhart_NEAStanfordApril2015.pdf

Bashmakov I, Bruckner T, Mulugetta Y, Chum H, Navarro A, Edmonds J (2014), 'Energy systems', In: Edenhofer O, PichsMadruga R, Sokona Y (eds), Climate change 2014: mitigation 
of climate Change, Cambridge University Press, New York. http://www.ipcc.ch/pdf/assessment-report/ar5/wg3/ipcc_ wg3_ar5_chapter7.pdf

Billinton R \& Allan RN (1996) Reliability evaluation of power systems, 2nd edn, Springer, New York

Bogdanov D, Breyer C (2016) 'North-East Asian Super Grid for $100 \%$ renewable energy supply: optimal mix of energy technologies for electricity, gas and heat supply options'. Energy Convers Manag 112:176-190

Brown T, Faruqui A (2014), Structure of electricity distribution network tariffs: recovery of residual costs. The Brattle Group, Sydney

Brown JH, Burnside WR, Davidson AD, DeLong JP, Dunn WC, Hamilton MJ, Mercado-Silva N, Nekola JC, Okie JG, Woodruff WH (2011) 'Energetic limits to economic growth'. Bioscience 61(1):19-26

Budischak C, Sewell D, Thomson H, Mach L, Veron DE, Kempton W (2012) 'Cost-minimized combinations of wind power, solar power and electrochemical storage, powering the grid up to $99.9 \%$ of the time'. J Power Sources 225:60-74

Buenstorf G (2004) The economics of energy and the production process: an evolutionary approach. Edward Elgar Publishing, Cheltenham

Bundesministerium für Wirtschaft und Technologie (2015) 'Generating capacity, gross electricity generation and gross consumption Germany', viewed 10 Feb 2016. Federal Ministry for Economic Affairs and Energy. http://www.bmwi.de/ $\mathrm{BMWi} /$ Redaktion/Binaer/Energiedaten/energietraeger10stromerzeugungskapazitaeten-bruttostromerzeugung,property $=$ blob, bereich $=$ bmwi2012, sprache $=$ de, $r w b=$ true.xls

Carbajales-Dale M, Barnhart CJ, Benson SM (2014) 'Can we afford storage? A dynamic net energy analysis of renewable electricity generation supported by energy storage'. Energy Environ Sci 7(5):1538-1544

Carbajales-Dale M, Raugei M, Fthenakis V, Barnhart C (2015) 'Energy return on investment (EROI) of solar PV: an attempt at reconciliation'. Proc IEEE 103(7):995-999

Cowen R (2005) Exploiting the Earth. Johns Hopkins University Press (unpublished). http://mygeologypage.ucdavis.edu/ cowen/ gel115/salt.html

Crawford RH (2009) 'Life cycle energy and greenhouse emissions analysis of wind turbines and the effect of size on energy yield'. Renewable Sustain Energy Rev 13(9):2653-2660

Dale M, Benson SM (2013) 'Energy balance of the global photovoltaic $(\mathrm{PV})$ industry-is the PV industry a net electricity producer?' Environ Sci Technol 47(7):3482-3489

Denholm P, Hand M (2011) 'Grid flexibility and storage required to achieve very high penetration of variable renewable electricity'. Energy Policy 39(3):1817-1830

Denholm P, Kulcinski GL (2004) 'Life cycle energy requirements and greenhouse gas emissions from large scale energy storage systems'. Energy Convers Manag 45(13):2153-2172

Denholm P, O'Connell M, Brinkman G, Jorgenson J (2015), Overgeneration from solar energy in California: a field guide to the Duck Chart. NREL (National Renewable Energy Laboratory (NREL), Golden, http://www.nrel.gov/docs/fy16osti/65023. pdf

Diamond JM (2005) Guns, germs, and steel, vintage, London

Edenhofer O, Pichs-Madruga R, Sokona Y, Farahani E (2014), 'Summary for Policymakers', In: Edenhofer O, Pichs-Madruga R, Sokona Y, Farahani E, Kadner S, Seyboth K, Adler A, Baum I, Brunner P, P Eickemeier KB, Savolainen J, Schlömer S, von Stechow C, Zwickel T, Minx JC (eds), Climate change 2014: mitigation of climate change. contribution of working group III to the Fifth assessment report of the intergovernmental panel on climate change, Cambridge University Press, New York. http:// www.ipcc.ch/pdf/assessment-report/ar5/wg3/ipcc_wg3_ar5_ summary-for-policymakers.pdf

Ellingsen LAW., Majeau-Bettez G, Singh B, Srivastava AK, Valøen LO, Strømman AH (2014) 'Life cycle assessment of a lithiumion battery vehicle pack'. J Ind Ecol 18(1):113-124

Elliston B, Diesendorf M, MacGill I (2012) 'Simulations of scenarios with $100 \%$ renewable electricity in the Australian National electricity market'. Energy Policy 45:606-613

Enevoldsen MK, Ryelund A, Andersen MS (2009) 'The impact of energy taxes on competitiveness: a panel regression study of 56 European industry sectors'. In: Andersen MS, Ekins P (eds) Carbon-energy taxation. Oxford Univeristy Press, New York

Gaines L (2014) 'The future of automotive lithium-ion battery recycling: charting a sustainable course'. Sustain Mater Technol $1: 2-7$

Götz M, Lefebvre J, Mörs F, Koch AM, Graf F, Bajohr S, Reimert R, Kolb T (2016) 'Renewable Power-to-Gas: a technological and economic review'. Renewable Energy 85:1371-1390

Gross R, Heptonstall P, Anderson D, Green T, Leach M, Skea J (2006), The Costs and impacts of intermittency: an assessment of the evidence on the costs and impacts of intermittent generation on the British electricity network. UK Energy Research Centre, London

Grossmann W, Grossmann I, Steininger KW (2015) 'Solar electricity supply isolines of generation capacity and storage'. Proc Natl Acad Sci USA 112(12):3663-3668

Hall D, Lee R (2014), Assessment of opportunities for new united states pumped storage hydroelectric plants using existing water features as auxiliary reservoirs. Idaho National Laboratory (INL), Idaho Falls

Hall CAS, Balogh S, Murphy DJR (2009) 'What is the minimum EROI that a sustainable society must have?' Energies 2(1):25-47

Hart EK, Stoutenburg ED, Jacobson MZ (2012) 'The potential of intermittent renewables to meet electric power demand: current methods and emerging analytical techniques'. Proc IEEE 100(2):322-334

Henning H-M, Palzer A (2014) 'A comprehensive model for the German electricity and heat sector in a future energy system with a dominant contribution from renewable energy technologies-part I: methodology'. Renewable Sustain Energy Rev 30:1003-1018

Hibbs DA, Olsson O (2004) 'Geography, biogeography, and why some countries are rich and others are poor'. Proc Natl Acad Sci USA 101(10):3715-3720

Huva R, Dargaville R, Rayner P (2016) 'Optimising the deployment of renewable resources for the Australian NEM (National Electricity Market) and the effect of atmospheric length scales'. Energy 96:468-473

IEEE (2007), IEEE Std 762-2006 - IEEE Standard Definitions for Use in Reporting Electric Generating Unit Reliability, Availability, and Productivity. IEEE Power Engineering Society, New York

International Energy Agency (IEA) (2014) Technology roadmapconcentrating solar power. IEA, Paris. https://www.iea.org/publications/freepublications/publication/TechnologyRoadmapSola rThermalElectricity_2014edition.pdf

International Energy Agency (IEA) (2016) Key world energy statistics-2016. IEA, Paris. https://www.iea.org/publications/ freepublications/publication/KeyWorld2016.pdf

International Renewable Energy Agency (IRENA) (2012), Concentrating solar power. IRENA, Abu Dhabi. http://www.irena.org/ documentdownloads/publications/re_technologies_cost_analysis-csp.pdf

Jacobson MZ, Delucchi MA, Cameron MA, Frew BA (2015), 'Low-cost solution to the grid reliability problem with $100 \%$ 
penetration of intermittent wind, water, and solar for all purposes'. Proc Natl Acad Sci, 112:15060-15065

Joas F, Pahle M, Flachsland C, Joas A (2016) 'Which goals are driving the energiewende? Making sense of the German energy transformation'. Energy Pol 95:42-51

Jorgenson DW (1984) 'The role of energy in productivity growth'. Energy J 5(3):11-26

King CW, Maxwell JP, Donovan A (2015) 'Comparing world economic and net energy metrics, part 1: single technology and commodity perspective'. Energies 8(11):12949-12974

Krause F, Bossel H, Müller-Reißmann K-F (1981), Energie-wende: wachstum und wohlstand ohne erdöl und uran, S. Fischer, Berlin

Krey V, Clarke L (2011) 'Role of renewable energy in climate mitigation: a synthesis of recent scenarios'. Climate Pol 11(4):1131-1158

Kubiszewski I, Cleveland CJ, Endres PK (2010) 'Meta-analysis of net energy return for wind power systems'. Renewable Energy 35(1):218-225

Lambert JG, Hall CA, Balogh S, Gupta A, Arnold M (2014) 'Energy, EROI and quality of life'. Energy Pol 64:153-167

Laudan R (2015) Cuisine and Empire: Cooking in World History. University of California Press, Berkeley

Lenzen M, McBain B, Trainer T, Jütte S, Rey-Lescure O, Huang J (2016) 'Simulating low-carbon electricity supply for Australia'. Appl Energy 179:553-564

Luo X, Wang J, Dooner M, Clarke J (2015) 'Overview of current development in electrical energy storage technologies and the application potential in power system operation'. Appl Energy 137:511-536

MacDonald AE, Clack CT, Alexander A, Dunbar A, Wilczak J, Xie Y (2016a) 'Future cost-competitive electricity systems and their impact on US $\mathrm{CO}_{2}$ emissions'. Nat Clim Change 6:526-531

MacDonald AE, Clack CT, Alexander A, Dunbar A, Wilczak J, Xie Y (2016b) 'Supplementary information: future cost-competitive electricity systems and their impact on US $\mathrm{CO}_{2}$ emissions'. Nat Clim Change 6:526-531

MacKay D (2008) Sustainable Energy-without the hot air. UIT, Cambridge

Maubach K-D (2014) Energiewende: wege zu einer bezahlbaren energieversorgung, Springer, Berlin

McConnell D, Forcey T, Sandiford M (2015) 'Estimating the value of electricity storage in an energy-only wholesale market'. Appl Energy 159:422-432

Morgan J (2014) 'The catch-22 of energy storage', Chem Aust, 2014:22

Morris C, Jungjohann A (2016) Energy democracy: Germany's Energiewende to renewables. Springer, Berlin

Moss RH, Edmonds JA, Hibbard KA, Manning MR, Rose SK, Van Vuuren DP, Carter TR, Emori S, Kainuma M, Kram T (2010) 'The next generation of scenarios for climate change research and assessment'. Nature 463(7282):747-756

Murphy DJ, Hall CA (2010) 'Year in review-EROI or energy return on (energy) invested'. Ann N Y Acad Sci 1185(1):102-118

Murphy DJ, Hall CA, Dale M, Cleveland C (2011) 'Order from chaos: a preliminary protocol for determining the EROI of fuels'. Sustainability 3(10):1888-1907

MWH (2009), Technical analysis of pumped storage and integration with wind power in the pacific northwest : MWH-HDC-T12, MWH Americas, Inc., Bellevue, http://www.hydro.org/wpcontent/uploads/2011/07/PS-Wind-Integration-Final-Reportwithout-Exhibits-MWH-3.pdf

Neubauer JS, Pesaran A, Williams B, Ferry M, Eyer J (2012), A techno-economic analysis of PEV battery second use: repurposed-battery selling price and commercial and industrial end-user value, SAE Technical Paper, 0148-7191, http://papers. sae.org/2012-01-0349/

North American Electric Reliability Corporation (NERC) 2011, Planning resource adequacy analysis, assessment and documentation. BAL-502-RFC-02, NERC, Washington DC, http://www. nerc.com/files/BAL-502-RFC-02.pdf

Nykvist B, Nilsson M (2015) 'Rapidly falling costs of battery packs for electric vehicles'. Nat Clim Change 5(4):329-332

OFGEM (2013), Electricity capacity assessment report 2013. OFGEM, London

Oswald J, Raine M, Ashraf-Ball H (2008) 'Will British weather provide reliable electricity?' Energy Pol 36(8):3212-3225

Palmer G (2013) 'Household solar photovoltaics: supplier of marginal abatement, or primary source of low-emission power?' Sustainability 5(4):1406-1442

Palzer A, Henning H-M (2014) 'A comprehensive model for the German electricity and heat sector in a future energy system with a dominant contribution from renewable energy technologiespart II: results'. Renewable Sustain Energy Rev 30:1019-1034

Pickard WF (2012) 'The history, present state, and future prospects of underground pumped hydro for massive energy storage'. Proc IEEE 100(2):473-483

Pickard WF (2014a) 'Energy return on energy invested (EROI): a quintessential but possibly inadequate metric for sustainability in a solar-powered world? [point of view]'. Proc IEEE 102(8):1118-1122

Pickard WF (2014b) 'Smart grids versus the Achilles' heel of renewable energy: can the needed storage infrastructure be constructed before the fossil fuel runs out?' Proc IEEE 102(7):1094-1105

Pirker O, Argyrakis I, Babkin V, Chudy M, Crosnier G, Dahlback N, Gianatti R, Gomez Martin P, Gudnason EG, Hellsten K, Kreiss G, Nikolov I, Oesch P, o`Mahony B, Pala R, Reinig L, Kreikenbaum D, Polak D, Romer N, Saturka Z, Stanojevic V, Stettler A, Marin C, Freitas, J.C.T., Lobacz J, Weisrock G, Jenko J, SEELOS K, Timm M. 2011, Hydro in Europe: powering renewables, Eurelectric, Brussels

Poser H, Altman J, ab Egg F, Granata A, Board R (2014), 'Development and integration of renewable energy: Lessons learned from Germany'. Finadvice, FAA Financial Advisory, Soodstrasse 55

Preston EG, Grady WM, Baughman ML (1997) 'A new planning model for assessing the effects of transmission capacity constraints on the reliability of generation supply for large nonequivalenced electric networks'. IEEE Trans Power Syst 12(3):1367-1373

Preston G (2015a) 100\% solar and wind power simulation for ERCOT, http://egpreston.com/100percentrenewables.pdf

Preston G (2015b) 'A simple calculation procedure for LOLE, LOLH, and EUE, calculation of probabilistic transmission line flows, and study results for extreme renewables in ERCOT', Paper presented to Institute of Electrical and Electronics Engineers (IEEE) LOLE Working Group, Golden, http://egpreston.com/ Presentation3.pdf

Preston G (2016a) 'Direct calculation example convolving ten randomly outaged generators', viewed Dec 1 2015, http://egpreston.com/DC.txt

Preston G (2016b) 'Microgrids Can Play An Important Role In Reducing ERCOT's Fossil Fuel Dependency', Renewable Energy Law Conference, http://egpreston.com/PrestonFeb2016. pdf

PV Education (2016) Average Solar Radiation, http://www.pveducation.org/pvcdrom/average-solar-radiation

Raugei M (2013) 'Comments on" energy intensities, EROIs (energy returned on invested), and energy payback times of electricity generating power plants"-making clear of quite some confusion'. Energy, 59:781 
Raugei M, Fullana-i-Palmer P, Fthenakis V (2012) 'The energy return on energy investment (EROI) of photovoltaics: methodology and comparisons with fossil fuel life cycles'. Energy Pol 45:576-582

Reedman LJ (2012) High penetration renewables studies: a review of the literature, report prepared for the Australian energy market operator (AEMO), report no. EP 127113. CSIRO, Melbourne. https://publications.csiro.au/rpr/download?pid=csiro:EP127113 $\& \mathrm{dsid}=\mathrm{DS} 2$

Riahi K, Grübler A, Nakicenovic N (2007) 'Scenarios of long-term socio-economic and environmental development under climate stabilization'. Technol Forecast Soc Change 74(7):887-935

Richa K, Babbitt CW, Nenadic NG, Gaustad G (2015) 'Environmental trade-offs across cascading lithium-ion battery life cycles'. Int J Life Cycle Assess. doi:10.1007/s11367-015-0942-3pp

Rosenberg N (1994) Exploring the black box: technology, economics, and history. Cambridge University Press, New York

Rydh CJ, Sandén BA (2005) 'Energy analysis of batteries in photovoltaic systems. Part I: performance and energy requirements'. Energy Convers Manag 46(11):1957-1979

Salles M, Aziz M, Hogan W (2016) 'Potential arbitrage revenue of energy storage systems in PJM during 2014', In:In Proceedings of the 2016 IEEE PES General Meeting (PIPGS16), Boston

Schiebahn S, Grube T, Robinius M, Tietze V, Kumar B, Stolten D (2015) 'Power to gas: Technological overview, systems analysis and economic assessment for a case study in Germany'. Int $\mathbf{J}$ Hydrog Energy 40(12):4285-4294

Schramski JR, Gattie DK, Brown JH (2015) 'Human domination of the biosphere: Rapid discharge of the earth-space battery foretells the future of humankind'. Proc Natl Acad Sci USA 112(31):9511-9517

Schreiber M, Wainstein ME, Hochloff P, Dargaville R (2015) 'Flexible electricity tariffs: power and energy price signals designed for a smarter grid'. Energy 93:2568-2581

Schurr SH (1990) Electricity in the American economy: Agent of technological progress. Greenwood Publishing Group, Westport

Sims RE, Schock RN, Adegbululgbe A, Fenhann JV, Konstantinaviciute I, Moomaw W, Nimir HB, Schlamadinger B, TorresMartínez J, Turner C (2007) 'Energy supply', In: Climate change 2007: Mitigation. Contribution of working group iii to the fourth assessment report of the intergovernmental panel on climate change, Cambridge University Press, New York. http:// www.ipcc.ch/publications_and_data/ar4/wg3/en/ch4.html

Sims R, Mercado P, Krewitt W, Bhuyan G, Flynn D, Holttinen H, Jannuzzi G, Khennas S, Liu Y, Nilsson LJ (2011), 'Integration of renewable energy into present and future energy systems', In: Edenhofer O, Pichs-Madruga R, Sokona Y (eds), IPCC special report on renewable energy sources and climate change mitigation, Cambridge University Press, New York. http://www.ipcc. $\mathrm{ch} / \mathrm{pdf} / \mathrm{special-reports/srren/Chapter} 8$ Integration of Renewable Energy into Present and Future Energy Systems.pdf

Sterner M (2009) Bioenergy and renewable power methane in integrated $100 \%$ renewable energy systems: limiting global warming by transforming energy systems. vol 14, Universität Kassel, Kassel

The University of Texas at Austin (2016), 'Texas Solar Radiation Database', viewed 31 March 2016, http://www.me.utexas. edu/ solarlab/tsrdb/tsrdb.html.

United States Department of Energy (DOE) (2016) DOE Global Energy Storage Database, viewed 10 Sep 2015, http://www. energystorageexchange.org/projects/data_visualization

US Energy Information Administration (EIA) (2015) ElectricityForm EIA-923 detailed data, http://www.eia.gov/electricity/ data/eia923/index.html

van der Burg, L., Pickard, S (2015) G20 subsidies to oil, gas and coal production: Germany, Oil Change International, Washington, DC

Weißbach D, Ruprecht G, Huke A, Czerski K, Gottlieb S, Hussein A (2013) 'Energy intensities, EROIs (energy returned on invested), and energy payback times of electricity generating power plants'. Energy 52:210-221

Wrigley EA (2010) Energy and the English industrial revolution. Cambridge University Press, New York

Yang C-J, Jackson RB (2011) 'Opportunities and barriers to pumpedhydro energy storage in the United States'. Renewable Sustain Energy Rev 15(1):839-844

Zackrisson M, Avellán L, Orlenius J (2010) 'Life cycle assessment of lithium-ion batteries for plug-in hybrid electric vehicles-Critical issues'. J Cleaner Prod 18(15):1519-1529 